\title{
A Case Report on the Management of Intractable Chyle Leakage after Left Neck Level V Lymph Node Biopsy
}

\author{
Somi Ryu ${ }^{1}$, Byeong Min Lee ${ }^{1}$, Seongjun Won ${ }^{1} \mathbb{D}$, and Jung Je Park ${ }^{1,2} \mathbb{D}$ \\ ${ }^{1}$ Department of Otorhinolaryngology, Gyeongsang National University School of Medicine, Gyeongsang National University Hospital, \\ Jinju; and ${ }^{2}$ Institute of Health Sciences, Gyeongsang National University, Jinju, Korea
}

\author{
흥관색전술로 치료한 난치성 유미유출 1예 \\ 류소미 ${ }^{1} \cdot$ 이병민 ${ }^{1} \cdot$ 원성준 $^{1} \cdot$ 박정제 $^{1,2}$ \\ 경상대학교 의과대학 경상대학교병원 이비인후과학교실, ${ }^{1}$ 경상대학교 건강과학연구원 ${ }^{2}$
}

\author{
Received February 1, 2020 \\ Revised March 26, 2020 \\ Accepted April 3, 2020 \\ Address for correspondence \\ Jung Je Park, MD, PhD \\ Department of Otorhinolaryngology, \\ Gyeongsang National University \\ Hospital, Gyeongsang National \\ University School of Medicine, \\ 79 Gangnam-ro, Jinju 52727, Korea \\ Tel $+82-55-750-8698$ \\ Fax +82-55-759-0613 \\ E-mail capetown@hanmail.net \\ Seongjun Won, MD \\ Department of Otorhinolaryngology, \\ Gyeongsang National University \\ Hospital, Gyeongsang National \\ University School of Medicine, \\ 79 Gangnam-ro, Jinju 52727, Korea \\ Tel $+82-55-750-8698$ \\ Fax +82-55-759-0613 \\ E-mail juni978@hanmail.net
}

Chyle leakage from the neck, which usually occurs after iatrogenic injury of the thoracic or lymphatic duct, is an uncommon complication of head and neck surgeries, which include neck dissection or thyroidectomy. A small amount of chyle leakage can be treated with conservative approaches, such as nutritional limitation, somatostatin analogues, and wound compression. However, massive or uncontrolled chyle leakage requires surgical exploration of the wound and thoracic duct ligation via the chest or transabdominal thoracic duct embolization can be applied. Here, we report a case of intractable massive chyle leakage in a 78-year-old male after a left neck level V lymph node biopsy, which was not controlled after conservative management and explorative surgery. Various treatment approaches were attempted and successful management of chyle leakage was ultimately achieved by thoracic duct embolization. Korean J Otorhinolaryngol-Head Neck Surg 2021;64(2):124-8

Key Words Chyle leakage $\cdot$ Thoracic duct embolization.

\section{Introduction}

Chyle is a type of milky body fluid that consists of lymph and emulsified fats or free fatty acids. Chyle leakage can occur when the lymphatic vessels are injured as a result of a malignancy, infection, congenital malformation, or iatrogenic injury, including surgery. ${ }^{1,2)}$ Indeed, chyle leakage is a well-

This is an Open Access article distributed under the terms of the Creative Commons Attribution Non-Commercial License (https://creativecommons.org/licenses/by-nc/4.0) which permits unrestricted non-commercial use, distribution, and reproduction in any medium, provided the original work is properly cited. known, albeit uncommon, complication of head and neck surgery that occurs in $1-2 \%$ of head and neck dissections. ${ }^{3,4)} \mathrm{Al}-$ though the incidence is low, it is important to consider this potential complication, as chyle leakage can lead to life-threatening conditions such as hypovolemia, metabolic disturbance, nutritional depletion, infection, and even death. ${ }^{5-7)}$ Initially, conservative management strategies can be attempted, such as a low fat diet, total parenteral nutrition, and somatostatin therapy, but surgical management with thoracic duct ligation or exploration and repair are required if conservative man- 
agement is not sufficient to prevent further leakage. ${ }^{8-10)}$ Less common approaches, such as radiation therapy and lymphatic embolization, can also be performed when chyle leakage is refractory to conservative management. ${ }^{11-13)}$ Thoracic duct embolization is not only effective but also minimally invasive, and shows a lower risk of complications than surgical approaches. ${ }^{11,12)}$ While there is no specific degree of chyle leakage that indicates the need for invasive treatment, exploratory surgery should be considered if leakage exceeds $500 \mathrm{~mL}$ per day, and other interventions are required if surgery is not successful.

Here, we describe a case of chyle leakage following cervical lymph node excisional biopsy, which was successfully treated with thoracic duct embolization after the failure of both conservative management and surgical exploration.

\section{Case}

A 78-year-old male receiving medication for hypertension and emphysema presented at the emergency room due to dyspnea, and scanty pericardial effusion was shown in chest
X-ray. Enhanced CT of the chest was performed, and suspicious lymph node metastasis was seen in the left neck (Fig. $1 \mathrm{~A}$ and $\mathrm{B})$, both in the supraclavicular area and mediastinum, as well as bone metastasis with pathologic fracture in the right rib. Fine needle aspiration and core needle biopsy are often the first procedures of cervical lymph node metastases; however, the patient wanted it to be precisely diagnosed at once so that he was asked for cervical lymph node excisional biopsy to confirm the presence of metastatic cancer to head and neck surgery department. Under local anesthesia, a lymph node (approximately $1 \mathrm{~cm}$ diameter) was removed from the left neck level V (Fig. 1C); there were no intraoperative complications, and the excised node was sent to the pathology department for further evaluation. The first post-operative date was uneventful, but swelling and oozing from the surgical site was observed on day 2 (Fig. 1D). The amount of fluid was not evaluated as drain had not been inserted, but more than 10 gauzes soaked with milky discharge were visible. On day 3, a Penrose drain was inserted, and massive chyle leakage was suspected due to the milky appearance of the fluid. Conservative management was initiated, including low
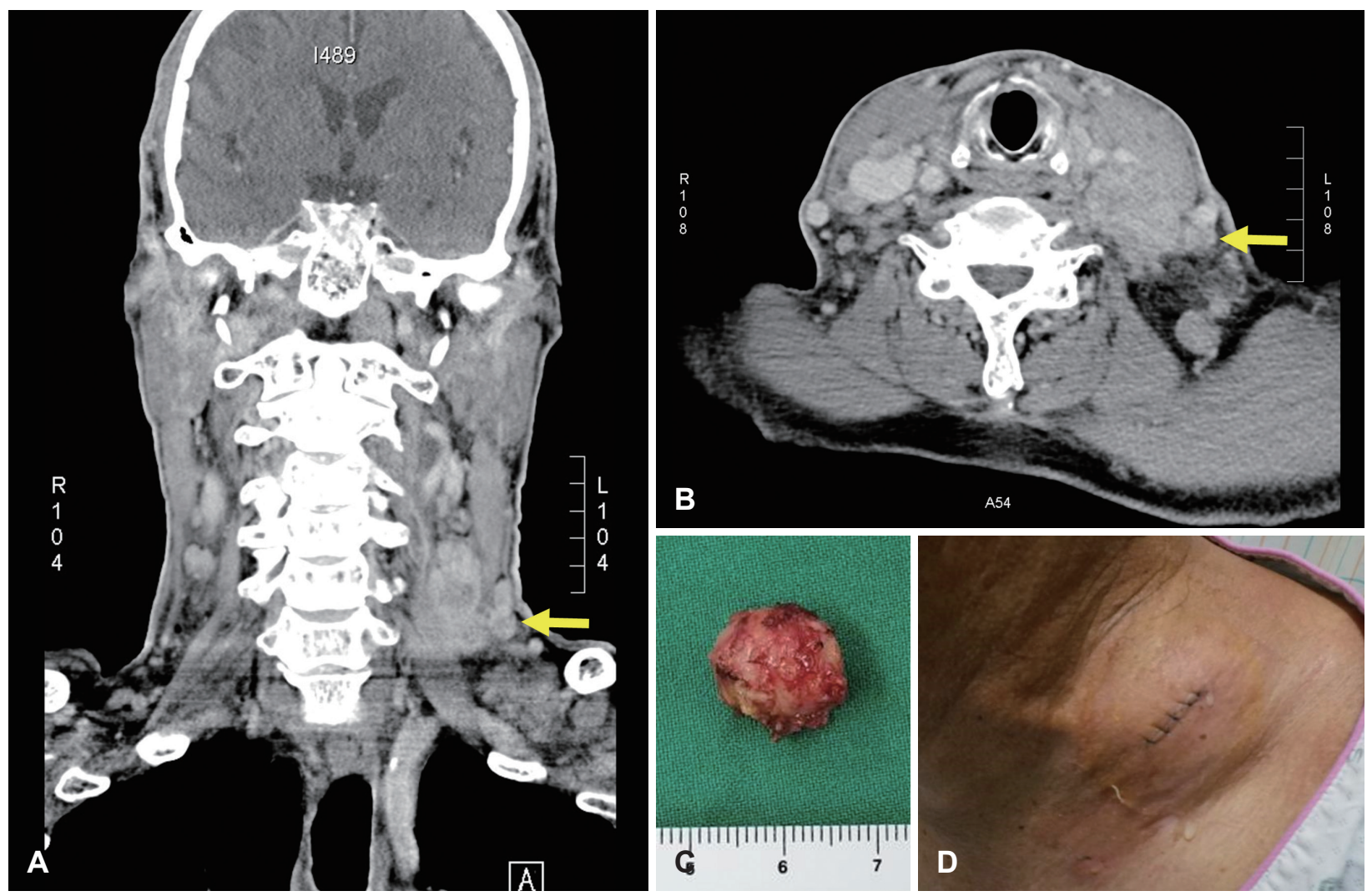

Fig. 1. Image findings of excised neck mass in the left neck. Conglomerate of lymph nodes in the left neck, which are suspected metastatic tumors. The arrow indicates a lymph node of approximately $1 \mathrm{~cm}$ diameter identified for excisional biopsy (A, B). Gross photograph of the excised lymph node (C). Swelling and oozing at the biopsy site on the second post-operative day (D). 



Fig. 2. Lymphangiogram before and after thoracic duct embolization. Lymphangiogram before embolization shows contrast leakage in the left neck (A). Lymphangiogram after thoracic duct embolization shows that chyle leakage has been prevented (B).

fat diet and treatment with octreotide (a somatostatin analogue). These measures were not sufficient to resolve the massive chyle leakage, and exploratory surgical intervention was performed on day 5. However, a definite leakage site could not be identified, and so surgical glue was applied diffusely in the operative field, and a Barovac drain was inserted. Meanwhile, pathological examination of the excised cervical lymph node confirmed that this was a metastatic nonsmall cell carcinoma. Only a small amount of chyle leakage was observed from the drain over the subsequent two days (11 and $75 \mathrm{cc}$ ). However, 3 days after exploratory surgery, $500 \mathrm{cc} /$ day of milky fluid was collected. Therefore, 13 days after the initial lymph node excision, surgical ligation and cauterization of the possible leakage site was performed. Despite conservative management and surgical exploration, no improvement in chyle leakage was seen, and the patient underwent thoracic duct embolization on post-operative day 16 (Fig. 2). Firstly, right inguinal lymph node was accessed under ultrasound guidance; thoracic duct was percutaneously accessed, and embolization was successfully done by interventional suite of the radiology department. Following this procedure, the volume of chyle leakage decreased markedly, and the neck wound was successfully closed on day 24 with no further complications. The post-operative hospital course of the patient is summarized in Fig. 3 .

\section{Discussion}

The incidence of chyle leakage from iatrogenic thoracic duct injury varies according to the site of surgery, but it has been reported to occur in 1-2\% of comprehensive neck dissections in patients with head and neck cancer., ${ }^{3,4)}$ Although several cases of chyle leakage after thyroidectomy or neck dissection have been reported, to the best of our knowledge the current case is the first to highlight a rare case of massive chyle leakage after neck level V lymph node excisional biopsy, which is likely to have been caused by an abnormally located thoracic duct due to the presence of the tumor (Fig. 2). Once the patient was considered for excisional biopsy of the conglomerate cervical lymph node with suspicious metastatic features, the possibility of chyle leakage was not considered because the location and size of the lymph node was not thought to have a difficult surgical approach. As lymphangiography prior to thoracic duct embolization showed that the lymphatic ducts were diffusely located in the excised lymph node, more careful approaches, such as core needle biopsy and excisional biopsy of the right cervical lymph node, may have avoided the surgical complications and resulted in a 


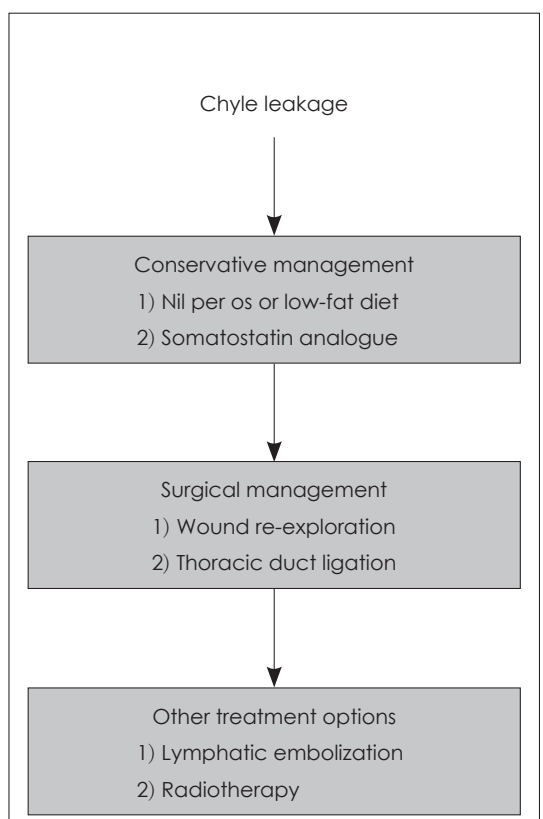

A

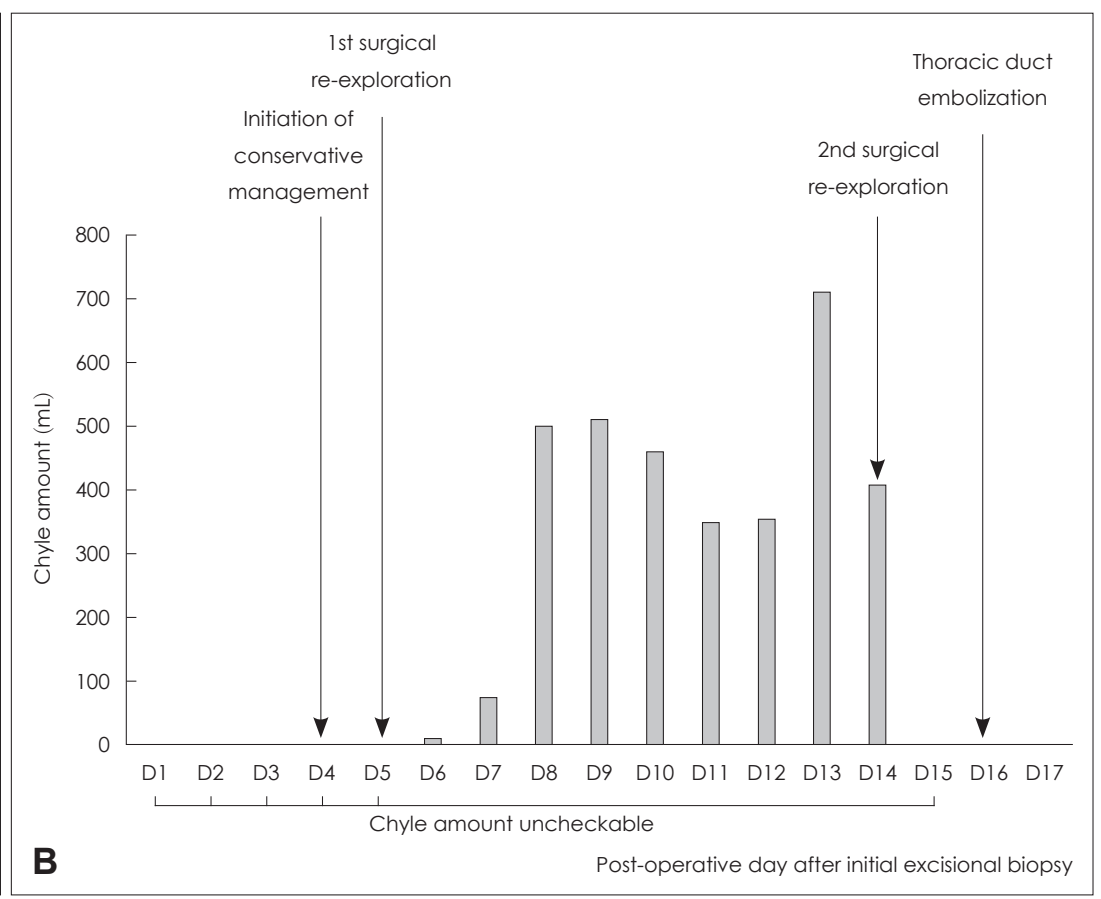

Fig. 3. Management of post-operative chyle leakage. Algorithm for the treatment of post-operative chyle leakage (A). Hospital course of the patient showing treatment option selection (B).

better outcome. This case emphasizes the importance of determining a diagnostic method for cervical lymph node enlargement or lymphadenopathy and of selecting the safest surgical approach, even when the targeted lymph node is easily palpable and located in a readily accessible cervical section. In the case outlined here, it was possible to start with a conservative management approach due to the stable general condition of the patient. However, invasive approaches should be considered early in the clinical course of patients with massive chyle leakage, as this acute condition can prove fatal. Our approach to treatment decision-making in the patient reported here is shown in Fig. 3.

The incidence of post-operative chyle leakage is low, but it may lead to conditions such as hypovolemia, metabolic disturbance, nutritional depletion, infection, and even death. ${ }^{5-7)}$ Conservative management strategies, such as low fat diet and the addition of somatostatin or its analogues, should be considered as the first treatment option in patients with massive chyle leakage following surgery, as they are known to be effective in approximately $23-100 \%$ of patients. ${ }^{1,14)}$ Somatostatin or its analogues are effective in this condition, as they reduce lymph flow in the lymphatic vessels. ${ }^{15,16)}$ Although the optimal duration of conservative management has not been established, Weniger, et al. ${ }^{14}$ have reported a median duration of 3.4-29.0 days until the resolution of chyle leakage. If massive chyle leakage (which is usually defined as $>500 \mathrm{~mL} /$ day) does not respond satisfactorily to conservative approaches, surgical control is generally considered necessary. ${ }^{1)}$ However, surgery can only be performed when the site of the leak can be identified, and this approach is associated with higher rates of complications such as sepsis, air embolism, and disseminated intravascular coagulation. Therefore, other techniques have been utilized for the treatment of chyle leakage, including radiotherapy and thoracic duct embolization. ${ }^{1,17)}$ While the reproducibility and success rate of thoracic duct embolization have not been satisfactory in the past, more recent reports have highlighted the potential of this approach in the management of high output chyle leakage. Indeed, three retrospective studies of 34, 109, and 105 patients demonstrated not only a low rate of morbidity and mortality, but also a high rate of effectiveness, with control of chyle leakage achieved in over $70 \%$ of patients $(70.6 \%, 71 \%$, and $79 \%$, respectively). ${ }^{18-20)}$ Based on these data, the decision to attempt thoracic duct embolization in our patient was made after conservative management and surgical re-exploration failed to prevent chyle leakage. On the basis of this report, we suggest that other treatment options, particularly thoracic duct embolization, should be considered when chyle leakage cannot be controlled with conservative management or when a definite leakage site cannot be identified.

In conclusion, surgeons treating neck masses must consider the possibility of chyle leakage not only after complex surgery, 
such as neck dissection and thyroidectomy, but also following cervical lymph node excisional biopsy. Treatment should be initiated as soon as chyle leakage is identified, and accurate evaluation of the patient's condition is important to guide decision-making regarding additional treatments once initial management approaches have failed.

\section{Acknowledgments}

None.

\section{Author Contribution}

Conceptualization: Jung Je Park. Data curation: Somi Ryu, Byeong Min Lee. Supervision: Seongjun Won, Jung Je Park. Writing — original draft: Somi Ryu, Seongjun Won. Writing — review \& editing: Seongjun Won.

\section{ORCIDs}

Jung Je Park

Seongjun Won

https://orcid.org/0000-0001-6325-0398 https://orcid.org/0000-0003-4163-4053

\section{REFERENCES}

1) Kim SW, Kim JH. Low-dose radiation therapy for massive chylous leakage after subtotal gastrectomy. Radiat Oncol J 2017;35(4):380-4.

2) Schild HH, Strassburg CP, Welz A, Kalff J. Treatment options in patients with chylothorax. Dtsch Arztebl Int 2013;110(48):819-26.

3) Ilczyszyn A, Ridha H, Durrani AJ. Management of chyle leak post neck dissection: A case report and literature review. J Plast Reconstr Aesthet Surg 2011;64(9):e223-30.

4) Scorza LB, Goldstein BJ, Mahraj RP. Modern management of chylous leak following head and neck surgery: A discussion of percutaneous lymphangiography-guided cannulation and embolization of the thoracic duct. Otolaryngol Clin North Am 2008;41(6):123140 , xi.

5) Cerfolio RJ. Chylothorax after esophagogastrectomy. Thorac Surg Clin 2006;16(1):49-52.

6) Marcon F, Irani K, Aquino T, Saunders JK, Gouge TH, Melis M. Percutaneous treatment of thoracic duct injuries. Surg Endosc 2011;25(9):2844-8.
7) Nair SK, Petko M, Hayward MP. Aetiology and management of chylothorax in adults. Eur J Cardiothorac Surg 2007;32(2):362-9.

8) Kim D, Cho J, Kim K, Shim YM. Chyle leakage patterns and management after oncologic esophagectomy: A retrospective cohort study. Thorac Cancer 2014;5(5):391-7.

9) Paul S, Altorki NK, Port JL, Stiles BM, Lee PC. Surgical management of chylothorax. Thorac Cardiovasc Surg 2009;57(4):226-8.

10) Shah RD, Luketich JD, Schuchert MJ, Christie NA, Pennathur A, Landreneau RJ, et al. Postesophagectomy chylothorax: Incidence, risk factors, and outcomes. Ann Thorac Surg 2012;93(3):897-903; discussion 903-4.

11) Atie M, Dunn G, Falk GL. Chlyous leak after radical oesophagectomy: Thoracic duct lymphangiography and embolisation (TDE)-a case report. Int J Surg Case Rep 2016;23:12-6.

12) Chen E, Itkin M. Thoracic duct embolization for chylous leaks. Semin Intervent Radiol 2011;28(1):63-74.

13) Sziklavari Z, Allgäuer M, Hübner G, Neu R, Ried M, Grosser C, et al. Radiotherapy in the treatment of postoperative chylothorax. J Cardiothorac Surg 2013;8:72.

14) Weniger M, D’Haese JG, Angele MK, Kleespies A, Werner J, Hartwig W. Treatment options for chylous ascites after major abdominal surgery: A systematic review. Am J Surg 2016;211(1): 206-13.

15) Collard JM, Laterre PF, Boemer F, Reynaert M, Ponlot R. Conservative treatment of postsurgical lymphatic leaks with somatostatin-14. Chest 2000;117(3):902-5.

16) Kuboki S, Shimizu H, Yoshidome H, Ohtsuka M, Kato A, Yoshitomi $\mathrm{H}$, et al. Chylous ascites after hepatopancreatobiliary surgery. Br J Surg 2013;100(4):522-7.

17) Aalami OO, Allen DB, Organ CH Jr. Chylous ascites: A collective review. Surgery 2000;128(5):761-78.

18) Itkin M, Kucharczuk JC, Kwak A, Trerotola SO, Kaiser LR. Nonoperative thoracic duct embolization for traumatic thoracic duct leak: Experience in 109 patients. J Thorac Cardiovasc Surg 2010;139(3):584-89; discussion 589-90.

19) Nadolski GJ, Itkin M. Thoracic duct embolization for nontraumatic chylous effusion: Experience in 34 patients. Chest 2013;143(1):15863.

20) Pamarthi V, Stecker MS, Schenker MP, Baum RA, Killoran TP, Suzuki Han A, et al. Thoracic duct embolization and disruption for treatment of chylous effusions: Experience with 105 patients. J Vasc Interv Radiol 2014;25(9):1398-404. 